\title{
Combined Embolization and Microsurgery for Cerebral Arteriovenous Malformation
}

\author{
Hiroyuki KinOUCHI, Kazuo MizOI, Akira TAKAHASHI*, \\ Masayuki EzURA**, and Takashi Yoshimoto***
}

\begin{abstract}
Department of Neurosurgery, Akita University School of Medicine, Akita; *Division
of Neuroendovascular Therapy, Department of Neurosciences, Tohoku University Graduate School of Medicine, Sendai; ${ }^{* *}$ Department of Neuroendovascular Therapy, Kohnan Hospital, Sendai; *** Department of Neurosurgery, Tohoku University School of Medicine, Sendai
\end{abstract}

\begin{abstract}
Thirty-seven of 396 patients with arteriovenous malformations (AVMs) were treated by preoperative embolization and surgical excision in our medical center between 1991 and 1997. The AVMs were Spetzler-Martin grade I in six, grade II in 11, grade III in 12, grade IV in four, and Grade V in four. A total of 69 embolization procedures were performed using estrogen alcohol and polyvinyl acetate as liquid embolization materials. AVM grades improved following embolization in 10 patients. Three hemorrhages occurred several days after the final embolization, probably due to hemodynamic stress on the unoccluded perforating feeders or drainer occlusion. Surgical resection was performed under guidance of intraoperative digital subtraction angiography. Although the AVMs were excised totally in one stage with no major neurological deficits, normal perfusion pressure breakthrough occurred in a patient with prominent collateral circulation of the AVM which developed after the main feeder embolization. Preoperative staged embolization with estrogen alcohol and polyvinyl acetate is effective to expand the surgical indication and to achieve complete resection of difficult AVMs. Direct surgery should be performed as soon as possible if hemodynamic changes are observed following embolization.
\end{abstract}

Key words: arteriovenous malformation, embolization, surgery, multimodality treatment

\section{Introduction}

Modern therapeutic modalities for arteriovenous malformation (AVM) including microneurosurgery, ${ }^{31,32)}$ intravascular neurosurgery, ${ }^{28,29)}$ and stereotactic radiosurgery ${ }^{2,14,20,23-25)}$ still have some limitations. However, the combination of these three modalities with the participation of specialists is expected to provide the maximum clinical benefits. ${ }^{4,9-}$ 11,15) In our center, endovascular embolization to reduce the AVM volume as much as possible is the first step in the treatment strategy of large or complex AVMs. ${ }^{16,17,33)}$ Subsequently, gamma knife therapy is indicated for AVMs located in the critical areas, and microsurgical resection is indicated for AVMs in surgically accessible locations. Here, we present our latest experiences with combined embolization with our liquid embolization materials and microsurgery for 37 patients with AVMs.

Received January 29, 2002; Accepted July 11, 2002

\section{Materials and Methods}

\section{Indications for embolization}

The initial treatment was selected according to the size of the nidus. The first choice was embolization if the nidus was more than $3 \mathrm{~cm}$ in diameter. However, preoperative embolization was performed for small AVMs of less than $3 \mathrm{~cm}$ in diameter if the AVMs were supplied by deep feeders that were difficult to access surgically.

\section{Patient population}

We treated 396 patients with AVMs in Tohoku University Medical Center from November 1991 to August 1997. The initial treatment was conventional neurosurgical resection for 16 AVMs, embolization for 149, and gamma knife radiosurgery for 231. Primary embolization in 149 AVMs was followed by no further treatment in 23 cases, gamma knife radiosurgery in 89 , and surgical resection in 37.

The 37 patients who underwent postembolization surgical removal of the residual AVM nidus includ- 
ed 13 females and 24 males, aged from 12 to 64 years (mean 38 years). Five AVMs were located in the basal ganglia and/or the thalamus, 26 in the cerebral cortex (eloquent 8, non-eloquent 18), and six in the cerebellum. The AVMs were classified according to the Spetzler and Martin scale ${ }^{22)}$ as grade I in six cases, grade II in 11, grade III in 12, grade IV in four, and grade $\mathrm{V}$ in four. Twenty patients presented with hemorrhage and nine with seizures. The other eight patients had headache, neurological deficits, or incidental discovery.

\section{Embolization technique}

Transfemoral catheterization was performed with the standard Seldinger's technique under local neuroleptanesthesia. A microcatheter including a calibrated leak balloon or mini catheter was introduced into the target feeding artery. The provocation test using amytal and xylocaine was performed to confirm no response. Embolization was then carried out using the chemical embolization materials developed in the Department of Neurosurgery, Tohoku University School of Medicine.6,7,18,26,27) Estrogen alcohol, a solution of conjugated estrogen in $25 \%$ ethanol ( $20 \mathrm{mg}$ estrogen in $1 \mathrm{ml}$ of $25 \%$ ethanol) is infused into the feeding pedicle to induce an intimal specific embolization effect, usually a dosage of 5-10 ml delivered by infusion pump for 10-20 minutes depending on the flow and anatomical characteristics of the feeding arterial system. ${ }^{18)}$ This infusion results in diffuse intimal cell damage and occlusion of the vessels and prevents future recanalization. Then an alcohol soluble polymer, polyvinyl acetate is injected under the real-time subtraction monitoring until the target vessel and the compartment of the nidus are obliterated. Polyvinyl acetate can be injected slowly or quickly, continuously or intermittently, and repeatedly through same catheter.

\section{Microsurgical resection}

The mean interval between the embolization procedure and direct surgery was 16 days. Surgical resection was performed under the guidance of intraoperative digital subtraction angiography (DSA). All AVMs were excised totally in one stage. This embolization method does not form a hard lesion and so causes no difficulties for the radical resection. Complete resection of AVMs was also confirmed by postoperative angiography in all patients 6 months after the surgery.

\section{Results}

\section{Embolization procedures}

A total of 69 embolization procedures were performed in the 37 patients (mean 1.9 per patient). Nidus embolization through the cortical feeding arteries was attempted in all patients. The perforating deep feeders were embolized in seven of 18 patients. The transcortical collateral vessels were identified in six patients and were embolized in one patient. The size of the nidus was reduced and the Spetzler and Martin grade improved following embolization in 10 patients.

Complications were divided into two categories according to the cause, hemorrhage and other factors. Three hemorrhages occurred in the early stage after the staged embolization (3-13 days), of which one occurred just after the craniotomy during the surgery. Drainer occlusion was suggested as the cause for the bleeding in one patient, and hemodynamic stress on the unoccluded perforating feeders after cortical artery embolization in the other two patients (Fig. 1). These hemorrhages resulted in permanent neurological deficits in two patients (visual field defect in 1, and sensory aphasia and hemiparesis in 1). Embolization-related infarction caused transient Gerstmann's syndrome in one patient after transcortical collateral vessel embolization, and permanent visual field defect in another patient after feeder embolization.

\section{Microsurgery}

Transient neurological deficits developed following microsurgical resection in five patients (hemiparesis in 2, visual field defect in 1, aphasia in 1, and Gerstmann's syndrome in 1), and the other two patients had permanent visual field defect. The Gerstmann's syndrome may have resulted from venous occlusion and the other complications were caused by surgical trauma during dissection of the AVMs from the eloquent areas. One patient with a large right frontal AVM showed transient hemiparesis caused by normal perfusion pressure breakthrough (NPPB) (Fig. 2). In this case, the transcortical collateral vessels from the middle cerebral artery (MCA) through the premotor cortex became dilated and prominent after embolization of the main feeders of the anterior cerebral arteries (ACAs). After resection of the nidus, the brain tissue supplied by transcortical collateral vessels became edematous and hemorrhagic. Consequently, the premotor area had to be evacuated. Fortunately, the final outcome was excellent. 


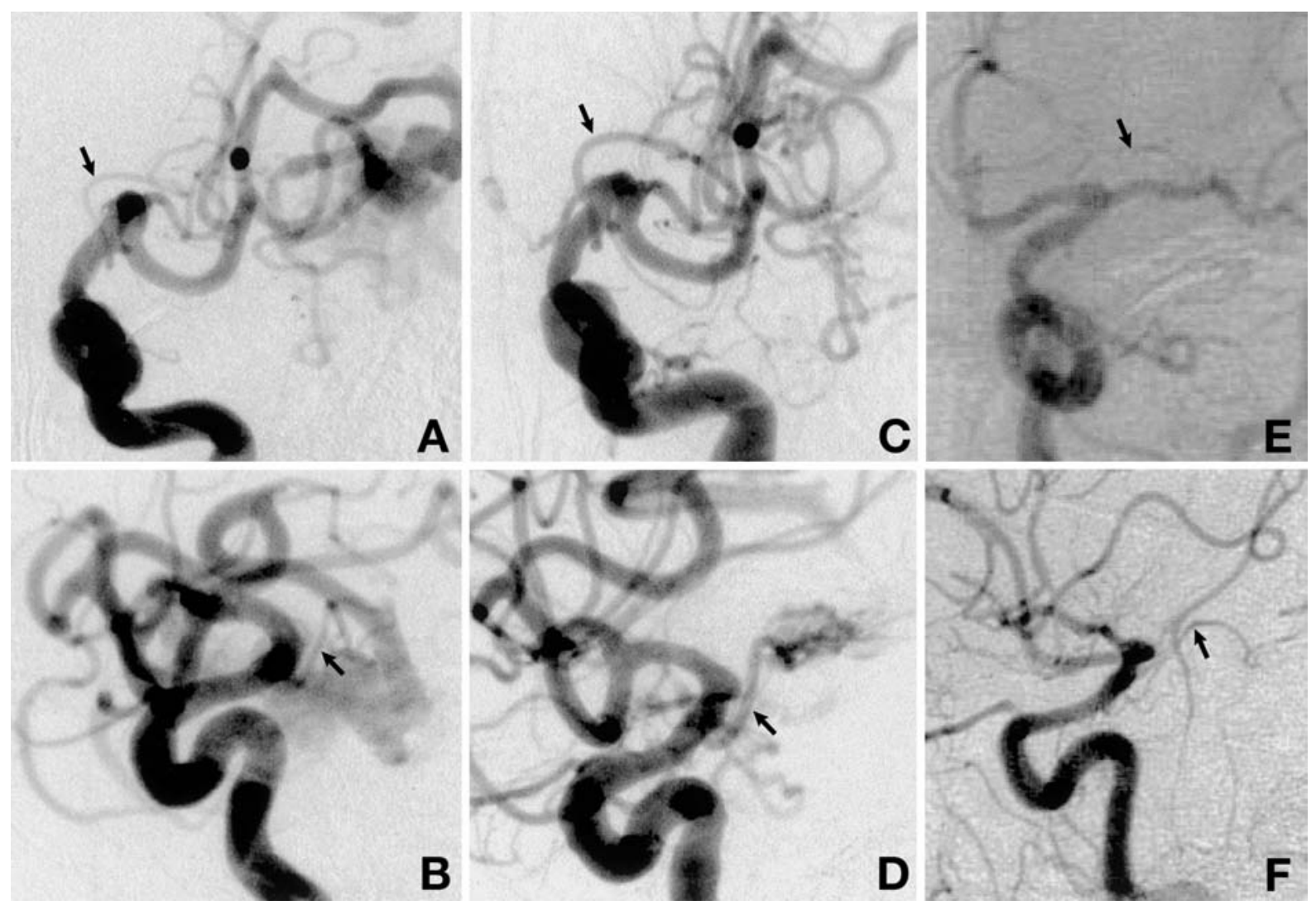

Fig. 1 Angiograms showing a left temporal arteriovenous malformation (AVM) in a 46-year-old man presenting with hemorrhage 3 days after the final embolization. Left internal carotid angiograms, anteroposterior (A) and lateral (B) views, before embolization demonstrating the AVM supplied by the middle cerebral artery and anterior choroidal artery (arrow). Left internal carotid angiograms, anteroposterior (C) and lateral (D) views, obtained immediately after the final embolization of the cortical feeders showing partial occlusion of the nidus and acute enlargement of the anterior choroidal artery (arrow). Postsurgical left internal carotid angiograms (E, F) showing complete resection of the AVM and decreased diameter of the anterior choroidal artery (arrow).

\section{Clinical outcome}

The clinical outcomes of the eight patients with high-grade AVMs (Spetzler and Martin grade IV or V) are summarized in Table 1. Three patients showed improvement in grade from IV or V to III following embolization. Six patients showed no neurological worsening after the final surgical resection. Two patients suffered visual field defect that was attributable to either embolization or surgery.

\section{Discussion}

\section{Embolization method}

The present AVM embolization method is known to be effective and safe. ${ }^{16,17,33)}$ Thirty-five of 144 patients $(24.3 \%)$ with AVMs embolized in Tohoku University Medical Center by 1994 showed near- total obliteration ( $\geq 95 \%$ occlusion), and 12 patients (8.3\%) showed complete nidus obliteration. ${ }^{33)}$ The mean nidus volume reduction was $51.8 \%$. In that series, follow-up angiography detected no recanalization of the nidus. Almost all patients showed one or two grade improvements according to the Spetzler and Martin grading system after embolization. The percentages of grade IV or V cases before and after embolization were $37 \%$ and $12 \%$, respectively. In the present series of 37 patients, AVM embolization resulted in grade improvement in 10 patients. Five of the eight cases classified as grade IV or $\mathrm{V}$ before embolization showed improvement and three cases became grade III. Therefore, these complex AVMs could be resected completely in one stage after the embolization with quite satisfactory results. 

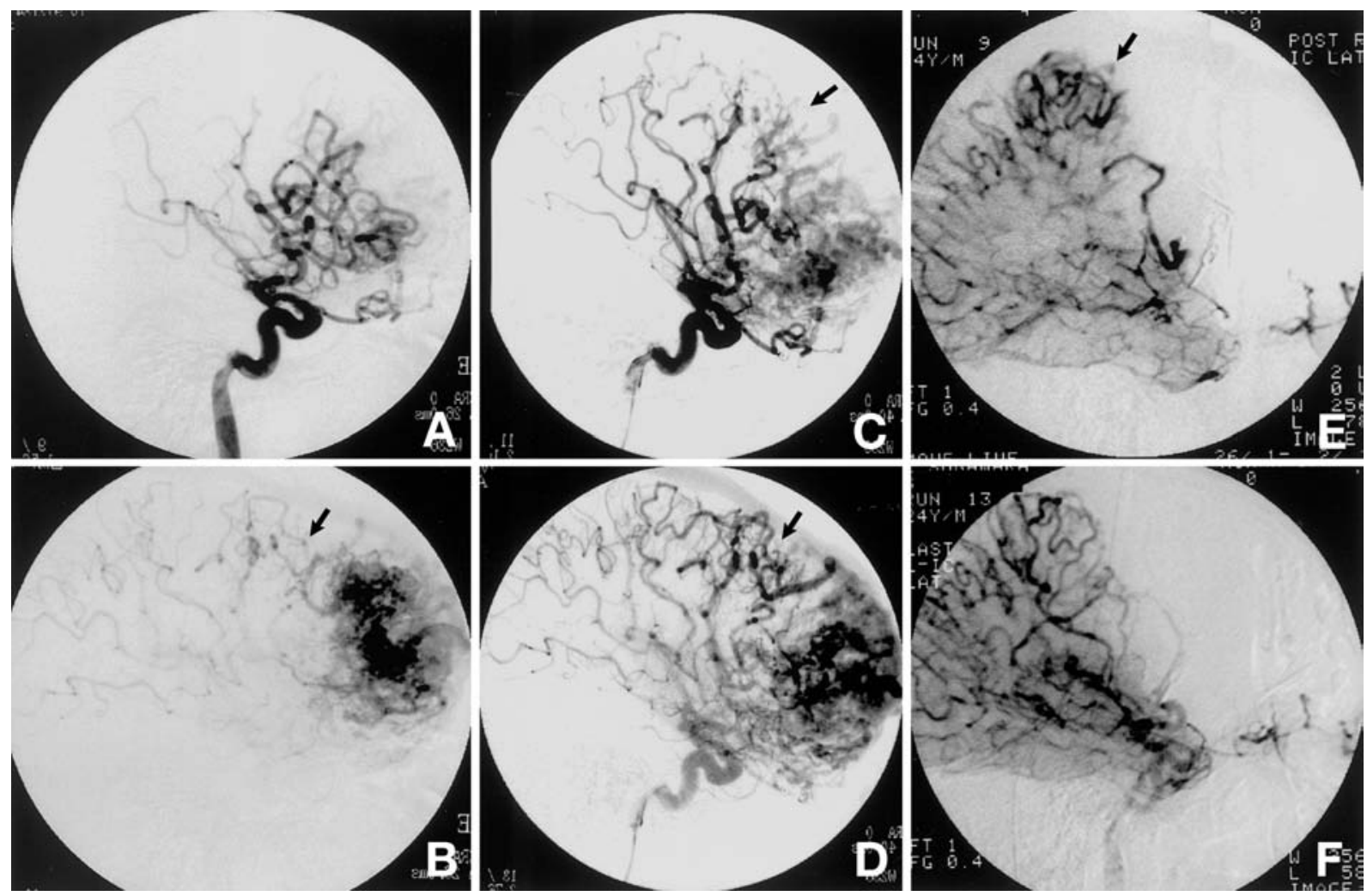

Fig. 2 Angiograms showing a large right frontal arteriovenous malformation (AVM) in a 24-year-old man presenting with seizure. Lateral right internal carotid angiograms, early (A) and late (B) arterial phases, before embolization showing a large AVM supplied by the anterior cerebral, middle cerebral (arrow), and lenticulostriate arteries. Lateral right internal carotid angiograms, early (C) and late (D) arterial phases, after embolization showing enlargement of the dilated transcortical collateral vessels (DTCVs) (arrow) from the middle cerebral artery through the premotor cortex. Intraoperative digital subtraction angiogram (DSA) (E) immediately after the resection of the nidus showing dilation and congestion of the DTCVs (arrow) induced supposedly by the normal perfusion pressure breakthrough mechanism. Final intraoperative DSA (F) showing disappearance of the DTCVs after resection of the edematous and hemorrhagic brain tissue.

Table 1 Clinical course of patients with high-grade arteriovenous malformations

\begin{tabular}{|c|c|c|c|c|c|c|c|c|}
\hline \multirow{2}{*}{$\begin{array}{l}\text { Case } \\
\text { No. }\end{array}$} & \multirow{2}{*}{$\begin{array}{c}\text { Age/ } \\
\text { Sex }\end{array}$} & \multirow{2}{*}{ Location } & \multirow{2}{*}{ Symptoms } & \multicolumn{2}{|c|}{ Grade* } & \multirow{2}{*}{ Complication } & \multicolumn{2}{|c|}{ Performance state } \\
\hline & & & & Before & After & & Admission & Discharge \\
\hline 1 & $14 / \mathrm{F}$ & rt cerebellum & ICH & $\mathrm{V}$ & III & none & MD & GR \\
\hline 2 & $24 / \mathrm{M}$ & rt cerebellum & ICH & $\mathrm{V}$ & IV & none & GR & GR \\
\hline 3 & $51 / \mathrm{M}$ & rt parietal & ICH & IV & IV & none & GR & GR \\
\hline 4 & $19 / \mathrm{M}$ & lt basal ganglia & ICH & IV & IV & none & SD & GR \\
\hline 5 & $12 / \mathrm{M}$ & lt thalamus & ICH & $\mathrm{V}$ & IV & none & SD & SD \\
\hline 6 & $18 / \mathrm{M}$ & lt occipital & seizure & IV & III & $\begin{array}{l}\text { visual field defect } \\
\text { (surgery) }\end{array}$ & GR & GR \\
\hline 7 & $31 / \mathrm{F}$ & rt occipital & headache & IV & III & $\begin{array}{l}\text { visual field defect } \\
\text { (embolization) }\end{array}$ & GR & GR \\
\hline 8 & $42 / \mathrm{F}$ & rt frontoparietal & $\mathrm{ICH}$ & $\mathrm{V}$ & $\mathrm{V}$ & none & SD & SD \\
\hline
\end{tabular}

*According to Spetzler and Martin scale. ${ }^{22}$ After: after embolization, before: before embolization, GR: good recovery, ICH: intracerebral hemorrhage, MD: moderately disabled, SD: severely disabled. 


\section{Hemorrhagic complications}

In the previous long-term follow-up study of 144 patients after embolization with estrogen alcohol and polyvinyl acetate, 105 patients were observed with or without gamma knife radiosurgery. Ten patients showed bleeding during the follow-up period (average 2.7 years). The cumulative hemorrhage rate after embolization was $2.82 \%$ year. ${ }^{33)}$ However, hemorrhage occurred at an early stage following embolization (3-13 days) in three patients in the present study. Fortunately, these hemorrhages caused no mortality, but one patient developed severe neurological deficits (hemiparesis and sensory aphasia). A multicenter trial to compare the safety and efficacy of n-butyl-2-cyanoacrylate (NBCA) with those of polyvinyl alcohol (PVA) for preoperative embolization of cerebral AVM found hemorrhagic complications in seven patients $(13.0 \%)$ in the NBCA group (54 patients) and 15 patients $(28.9 \%)$ in the PVA group (52 patients). ${ }^{19)}$ Hemorrhage occurred post-embolization in four patients $(7.4 \%)$ in the NBCA group and three patients (5.8\%) in PVA group. ${ }^{19)}$ The occurrence of hemorrhagic complications should be minimized, but the incidence of hemorrhage following embolization in the present study was not much greater than that reported previously.

\section{Hemodynamic change after embolization}

Progressive thrombosis of the AVM draining vein was suggested as one of the causes of the hemorrhagic complications following embolization. ${ }^{29)}$ In our series, one patient showed drainer occlusion following nidus embolization. Postembolization angiography showed that draining flow was intact in the other two patients, but that the deep perforating arteries supplying the AVM were enlarged after occlusion of the major cortical feeding arteries. Blocking the major feeding arteries leads to greater participation of the deeper perforating arteries. ${ }^{5,13)}$ Such acute hemodynamic stress may cause rupture of the remaining nidus. Therefore, surgical resection should be performed immediately if signs of such changes are identified by postembolization angiography.

Transcortical collateral arterial supply to the AVM, similar to the deep perforating arteries, sometimes develops after successful embolization. ${ }^{12,23)}$ This collateral pattern is slower in developing in most cases. ${ }^{12)}$ However, in our case of left frontal AVM, the transcortical collateral vessels developed immediately after the embolization of the feeding vessels. Transcortical collateral vessels on the premotor cortex via the MCA became prominent after embolization of the feeding ACAs. After resection of the nidus, the premotor cortex just adjacent to the nidus became edematous and hemorrhagic, supposedly due to the NPPB mechanism. Intraoperative DSA demonstrated massive enlargement and congestion of the transcortical collateral vessels during resection. Finally, the premotor cortex had to be resected. Fortunately, the patient showed only temporary hemiparesis. This result clearly demonstrates that incomplete feeder occlusion for an AVM with transcortical collateral vessels may cause adverse hemodynamic changes that are much more difficult to handle during surgery.

\section{Embolization materials}

Many types of embolization materials have been proposed, including detachable balloons, particles such as silastic, latex, and PVA, polymers such as isobutyl-2-cyanoacrylate (IBCA), NBCA, and ethylene vinyl alcohol copolymer, metallic coils, and threads. ${ }^{4)}$ PVA and NBCA are representative of these materials and are readily available. ${ }^{19,30)}$ Incomplete vessel or nidus occlusion by any method will result in revascularization and collateral formation, but PVA carries a greater risk in the long term of recanalization than NBCA even after complete obliteration. ${ }^{21)}$ In contrast, AVMs completely embolized with NBCA are stable. ${ }^{8,30}$ However, long-term follow-up angiography after embolization with estrogen alcohol and polyvinyl acetate detected no recanalization of the vessels filled with the embolic material. ${ }^{33)}$

NBCA carries the well-known risk unique to adhesive cyanoacrylate of gluing the catheter to the vessel. ${ }^{1,3)}$ Late polymerization of NBCA may occur, leading to venous passage and venous occlusion. However, estrogen alcohol and polyvinyl acetate cannot glue the catheter to body structures and we have not experienced any case of pulmonary embolism following embolization with these materials. $^{33)}$ In contrast to IBCA, the AVMs embolized with NBCA are elastic and easy to cut. ${ }^{19,29,30)}$ In addition, the surgeon did not consider that resection of the AVM nidus was significantly more difficult after NBCA embolization than after particle embolization. ${ }^{19,29,30)}$ Lesions embolized with the present method using estrogen alcohol and polyvinyl acetate are not hard and do not cause any difficulties for radical resection. ${ }^{33)}$ Finally, the parts of the nidus embolized by estrogen alcohol and polyvinyl acetate do not have to be resected because of the stability of the embolized vessels. We believe that this feature will reduce the surgical complication rate after embolization with this material. Therefore, intraoperative DSA is quite useful to decide the end point of surgery, and to confirm the complete angiographical 
obliteration of the AVM. ${ }^{16,17,33)}$

\section{Conclusion}

Preoperative staged embolization with liquid embolization materials (estrogen alcohol and polyvinyl acetate) is effective to reduce the surgical requirement and to expand the surgical indications for AVMs. However, hemodynamic changes in the unoccluded deep perforating arteries, transcortical collateral vessels, or draining vein following embolization indicate that direct surgery should be performed as soon as possible. Intraoperative DSA can improve the safety and effectiveness of AVM surgery.

\section{References}

1) Bank WO, Kerber CW, Cromwell LD: Treatment of arteriovenous malformations with isobutyl 2cyanoacrylate: initial clinical experience. Radiology 139: 609-616, 1981

2) Colombo F, Pozza F, Chierego G, Casentini L, De Luca G, Francescon P: Linear accelerator radiosurgery of cerebral arteriovenous malformations: an update. Neurosurgery 34: 14-21, 1994

3) Debrun GM, Aletich V, Shownkeen H, Ausman JI: Glued catheters during embolisation of brain AVMs with acrylic glue. Intervent Neuroradiol 3: 13-19, 1997

4) Deruty R, Pelissou-Guyotat I, Mottolese C, Bascoulergue Y, Amat D: The combined management of cerebral arteriovenous malformations. Experience with 100 cases and review of the literature. Acta Neurochir (Wien) 123: 101-112, 1993

5) Drake CG: Cerebral arteriovenous malformations: considerations for and experience with surgical treatment in 166 cases. Clin Neurosurg 26: 145-208, 1979

6) Ezura M, Takahashi A, Yoshimoto T: Successful treatment of an arteriovenous malformation by chemical embolization with estrogen followed by conventional radiotherapy. Neurosurgery 31: 11051107, 1992

7) Ezura M, Takahashi A, Yoshimoto T, Fujii Y, Park YJ: Hydrophilic polymer-coated guided wire combined with progressive suppleness pursil catheter for safer, more definitive embolization of arteriovenous malformations. Neuroradiology 36: 326-329, 1994

8) Gobin YP, Laurent A, Merienne L, Schlienger M, Aymard A, Houdart E, Casasco A, Lefkopoulos D, George B, Merland JJ: Treatment of brain arteriovenous malformations by embolization and radiosurgery. J Neurosurg 85: 19-28, 1996

9) Grzyska U, Westphal M, Zanella F, Freckmann N, Herrmann HD, Zeumer H: A joint protocol for the neurosurgical and neuroradiologic treatment of cerebral arteriovenous malformations: Indication, technique, and results in 76 cases. Surg Neurol 40:
476-484, 1993

10) Guo WY, Wikholm G, Karlsson B, Lindquist C, Svendsen P, Ericson K: Combined embolization and gamma knife radiosurgery for cerebral arteriovenous malformations. Acta Radiol 34: 600-606, 1993

11) Jafar JJ, Davis AJ, Berenstein A, Choi IS, Kupersmith MJ: The effect of embolization with N-butyl cyanoacrylate prior to surgical resection of cerebral arteriovenous malformations. J Neurosurg 78: 60-69, 1993

12) Luessenhop A, Presper JH: Surgical embolization of cerebral arteriovenous malformations through internal carotid and vertebral arteries. Long-term results. J Neurosurg 42: 443-451, 1975

13) Luessenhop AJ, Rosa L: Cerebral arteriovenous malformations. Indications for and results of surgery, and the role of intravascular techniques. J Neurosurg 60: 14-22, 1984

14) Lunsford LD, Kondziolka D, Flickinger JC, Bissonette DJ, Jungreis CA, Maitz AH, Horton JA, Coffey RJ: Stereotactic radiosurgery for arteriovenous malformation of the brain. J Neurosurg 75: 512-524, 1991

15) Marks MP, Lane B, Steinberg GK, Fabrikant JI, Levy RP, Frankel KA, Phillips MH: Endovascular treatment of cerebral arteriovenous malformations following radiosurgery. AJNR Am J Neuroradiol 14: 297-305, 1993

16) Mizoi K, Jokura H, Yoshimoto T, Takahashi A, Ezura M, Kinouchi H, Nagamine Y, Boku N: Multimodality treatment for large and critically located arteriovenous malformations. Neurol Med Chir (Tokyo) 38 (Suppl): 186-192, 1998

17) Mizoi K, Takahashi A, Yoshimoto T, Sugawara T, Saito K: Surgical excision of giant cerebellar hemispheric arteriovenous malformations following preoperative embolization. Report of two cases. J Neurosurg 76: 1008-1011, 1992

18) Nagamine $Y$, Komatsu S, Suzuki J: New embolization method using estrogen on microcirculation. Surg Neurol 20: 269-275, 1983

19) The n-BCA Trial Investigators: N-butyl cyanoacrylate embolization of cerebral arteriovenous malformations: results of a prospective, randomized, multicenter trial. AJNR Am J Neuroradiol 23: 748-755, 2002

20) Redekop GJ, Elisevich KV, Gaspar LE, Wiese KP, Drake CG: Conventional radiation therapy of intracranial arteriovenous malformations: long-term results. J Neurosurg 78: 413-422, 1993

21) Sorimachi T, Koike T, Takeuchi S, Minakawa T, Abe $\mathrm{H}$, Nishimaki K, Ito Y, Tanaka R: Embolization of cerebral arteriovenous malformations achieved with polyvinyl alcohol particles: angiographic reappearance and complications. AJNR Am J Neuroradiol 20: 1323-1328, 1999

22) Spetzler RF, Martin NA: A proposed grading system for arteriovenous malformations. J Neurosurg 65: 476-483, 1986 
23) Stein BM, Wolpert SM: Surgical and embolic treatment of cerebral arteriovenous malformations. Surg Neurol 7: 359-369, 1977

24) Steiner L, Lindquist C, Adler JR, Torner JC, Alves W, Steiner M: Clinical outcome of radiosurgery for cerebral arteriovenous malformations. J Neurosurg 77: 1-8, 1992

25) Steiner L, Lindquist C, Cail W, Karlsson B, Steiner M: Microsurgery and radiosurgery in brain arteriovenous malformations. J Neurosurg 79: 647-652, 1993

26) Sugawara T, Takahashi A, Su CC, Suga T, Yoshimoto $\mathrm{T}$ : Experimental investigation of a new liquid embolization method: Combined administration of estrogen-alcohol and polyvinyl acetate. Neurol Med Chir (Tokyo) 33: 71-76, 1993

27) Takahashi A, Suzuki J: Nonsurgical treatment of AVM: development of new liquid embolization method, in Suzuki J (ed): Advances in Surgery for Cerebral Stroke. Tokyo, Springer-Verlag, 1988, pp 215-224

28) Taki W, Yonekawa Y, Iwata H, Uno A, Yamashita K, Amemiya $\mathrm{H}$ : A new liquid material for embolization of arteriovenous malformations. AJNR Am J Neuroradiol 11: 163-168, 1990

29) Vinuela F, Dion JE, Duckwiler G, Martin NA, Lylyk P, Fox A, Pelz D, Drake CG, Girvin JJ, Debrun G: Combined endovascular embolization and surgery in the management of cerebral arteriovenous malforma- tions: Experience with 101 cases. J Neurosurg 75: 856-864, 1991

30) Wallace RC, Flom RA, Khayata MH, Dean BL, McKenzie J, Rand JC, Obuchowski NA, Zepp RC, Zabramski JM, Spetzler RF: The safety and effectiveness of brain arteriovenous malformation embolization using acrylic and particles: the experiences of a single institution. Neurosurgery 37: 606-618, 1995

31) Yoshimoto T, Kayama T, Suzuki J: Treatment of cerebral arteriovenous malformation. Neurosurg Rev 9: 279-285, 1986

32) Yoshimoto T, Suzuki J: [Surgical treatment of cerebral arteriovenous malformations]. Neurosurgeons (Proceeding of the Japanese Congress of Neurological Surgeons) 4: 281-287, 1985 (Jpn)

33) Yoshimoto T, Takahashi A, Kinouchi H, Mizoi K, Jokura $\mathrm{H}$ : Role of embolization in the management of arteriovenous malformations. Clin Neurosurg 92: 313-327, 1995

Address reprint requests to: H. Kinouchi, M.D., Department of Neurosurgery, Akita University School of Medicine, 1-1-1 Hondo, Akita 010-8543, Japan. e-mail: kinouchi@nsg.med.akita-u.ac.jp.

Commentary on this paper appears on the next page. 


\section{Commentary}

In this article, the authors analyzed the therapeutic results of combined preoperative embolization and microsurgery in 37 patients harboring intracranial arteriovenous malformations (AVM). Special liquid embolization materials, estrogen alcohol and polyvinyl acetate, were used for the embolization procedure. With these liquid materials, the authors found that the consistency of AVM was not changed after the embolization. Thus, they concluded that since these materials used did not result in hardening of the nidus, the microsurgical resection of the nidus after embolization was less complicated than when other embolization materials are used. The major complication of this study was three patients (8\%) with postembolization hemorrhage.

In our own series, a similar number (156) of patients underwent embolization. We used n-butyl-2cyanoacrylate (NBCA) as the embolization material. The total obliteration rate by embolization as the solo treatment modality is similar to the present study (14\%). However, the post-embolization bleeding rate is lower (2.8\%) and all bleeding occurred due to inappropriate occlusion of the venous outlet of the AVM. We had more patients (135) who underwent microsurgery as the subsequent treatment after embolization. We did not find any increased difficulty during the dissection of the nidus in patients with AVM embolized with NBCA.

Yong-Kwang TU, M.D. Department of Neurosurgery College of Medicine and Hospital National Taiwan University Taipei, Taiwan, R.O.C. 